This item was submitted to Loughborough's Research Repository by the author.

Items in Figshare are protected by copyright, with all rights reserved, unless otherwise indicated.

\title{
Antecedents of perceived coach autonomy supportive and controlling behaviors: coach psychological need satisfaction and well-being
}

\section{PLEASE CITE THE PUBLISHED VERSION}

http://journals.humankinetics.com/jsep-back-issues/jsep-volume-33-issue-2-april/antecedents-of-perceivedcoach-autonomy-supportive-and-controlling-behaviors-coach-psychological-need-satisfaction-and-well-being

\section{PUBLISHER}

(c) Human Kinetics, Inc.

\section{VERSION}

AM (Accepted Manuscript)

\section{LICENCE}

CC BY-NC-ND 4.0

\section{REPOSITORY RECORD}

Stebbings, Juliette, lan M. Taylor, and Christopher M. Spray. 2019. "Antecedents of Perceived Coach Autonomy Supportive and Controlling Behaviors: Coach Psychological Need Satisfaction and Well-being". figshare. https://hdl.handle.net/2134/15375. 
This item was submitted to Loughborough's Institutional Repository (https://dspace.lboro.ac.uk/) by the author and is made available under the following Creative Commons Licence conditions.

\section{creative
commons}

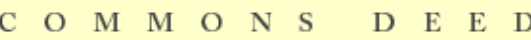

Attribution-NonCommercial-NoDerivs 2.5

You are free:

- to copy, distribute, display, and perform the work

Under the following conditions:

Attribution. You must attribute the work in the manner specified b the author or licensor.

Noncommercial. You may not use this work for commercial purposes.

No Derivative Works. You may not alter, transform, or build upon this work.

- For any reuse or distribution, you must make clear to others the license terms of this work.

- Any of these conditions can be waived if you get permission from the copyright holder.

Your fair use and other rights are in no way affected by the above.

This is a human-readable summary of the Leqal Code (the full license).

\section{Disclaimer 만}

For the full text of this licence, please go to: http://creativecommons.org/licenses/by-nc-nd/2.5/ 
1

2

3

4

5

6

7

Antecedents of Perceived Coach Autonomy Supportive and Controlling Behaviors:

8

Coach Psychological Need Satisfaction and Well-Being

9

10

Date submitted: XXXXXXXX, 2010

12

Date resubmitted: October 6th, 2010

13

Date of third submission: December xxth, 2010

14 


\section{Abstract}

2 Within the self-determination theory (SDT; Deci \& Ryan, 2000) framework, research has

3 considered the consequences of coaches' autonomy supportive and controlling behaviors on

4 various athlete outcomes (e.g., motivation and performance). The antecedents of such

5 behaviors, however, have received little attention. Coaches $(N=443)$ from a variety of sports

6 and competitive levels completed a self-report questionnaire to assess their psychological

7 need satisfaction, well-being and perceived interpersonal behaviors towards their athletes.

8 Structural equation modeling demonstrated that coaches’ competence and autonomy need

9 satisfaction positively predicted their levels of psychological well-being, as indexed by

10 positive affect and subjective vitality. In turn, coaches' psychological well-being positively

11 predicted their perceived autonomy support towards their athletes, and negatively predicted

12 their perceived controlling behaviors. Overall, the results highlight the importance of

13 coaching contexts that facilitate coaches’ psychological need satisfaction and well-being,

14 thereby increasing the likelihood of adaptive coach interpersonal behavior towards athletes. 
Antecedents of Perceived Coach Autonomy Supportive and Controlling Behaviors: Coach Psychological Need Satisfaction and Well-Being A prominent social factor present in an athlete's sporting context is the coach (Horn, 2008), therefore, the interpersonal style employed by coaches has the potential to shape athletes’ sport experiences (Vallerand \& Losier, 1999). One theoretical framework that has frequently been employed to examine coach behaviors and the subsequent effects on athletes is self-determination theory (SDT; Deci \& Ryan, 2000), which distinguishes between autonomy supportive versus controlling interpersonal styles. An autonomy supportive environment is created when coaches offer their athletes opportunities for input and decisionmaking (e.g., choosing an appropriate tactic during a game), provide a sound rationale for tasks, and acknowledge athletes’ feelings and perspectives. In contrast, a controlling environment is created when coaches use power-assertive techniques to pressure athletes into thinking, feeling and behaving in certain ways (Mageau \& Vallerand, 2003). A controlling coach will act in a highly coercive and authoritarian manner (e.g., telling athletes how they will play the game), and will use criticism or tangible rewards to manipulate athletes. This type of coach will also issue punishments (e.g., extra running or exercise repetitions) and embarrass athletes (e.g., by emphasizing past mistakes) to force them to comply with the coach’s expectations and demands (Bartholomew, Ntoumanis, \& Thøgersen-Ntoumani, 2009). The two interpersonal styles have been shown to be moderately related (Pelletier, Fortier, Vallerand, \& Brière, 2001), yet an absence of autonomy support does not necessarily equate to high levels of control (Bartholomew, Ntoumanis, \& Thøgersen-Ntoumani, 2010). For example, a coach who adopts a laissez-faire approach is unlikely to be autonomy supportive or controlling. Research is required, therefore, that simultaneously examines these two contrasting interpersonal styles. 
A wealth of SDT-based research has indicated that many benefits exist for athletes

2 who have an autonomy supportive coach, such as enhanced psychological well-being, basic

3 psychological need satisfaction, self-determined motivation and performance (Amorose,

4 2007; Gillet, Vallerand, Amoura, \& Baldes, 2010; Mageau \& Vallerand, 2003). On the other

5 hand, the consequences for athletes who perceive their coach as controlling include poor

6 quality motivation and increased likelihood of dropping out (Pelletier et al., 2001).

7 Nevertheless, coaches frequently employ controlling and pressuring strategies (e.g., Fraser-

8 Thomas \& Côté, 2009). It is imperative, therefore, that researchers identify factors which

9 determine coaches' use of these interpersonal styles, so that an autonomy supportive style can

10 be promoted and controlling coaching styles diminished. To date, however, there is a dearth

11 of research addressing this line of inquiry. The purpose of the current study was to examine

12 potential precursors of perceived coach interpersonal behavior using SDT constructs; specifically, those proposed by basic psychological needs theory (BPNT; Deci \& Ryan,

14 2000), a sub-theory of the wider SDT framework. In particular, we wished to crosssectionally explore whether satisfying coaches’ psychological needs may lead them to behave towards athletes in a manner which enhances athletes’ sport experiences.

Advocates of BPNT assume that for humans to function and develop optimally, three psychological needs must be satisfied: competence, autonomy and relatedness. The need for competence is fulfilled when individuals perceive a sense of mastery through effectively interacting with their environment (Harter, 1978). The need for autonomy refers to the desire

21 to be self-initiating in the regulation of one's actions (deCharms, 1968). Lastly, the need for 22 relatedness concerns the desire to feel connected with, and mutually supportive of, significant 23 others (Baumeister \& Leary, 1995). A plethora of evidence exists suggesting that satisfaction 24 of these psychological needs leads to positive outcomes, such as persistence in sport 25 (Sarrazin, Vallerand, Guillet, Pelletier, \& Cury, 2002), positive exercise-related affect 
1 (Wilson, Mack, Blanchard, \& Gray, 2009), work performance and psychological adjustment

2 (Baard, Deci, \& Ryan, 2004). Nonetheless, very little research has extended this line of

3 inquiry to interpersonal behavior. As an exception, Taylor, Ntoumanis, and Standage (2008)

4 reported that satisfaction of physical education teachers' psychological needs was positively

5 associated with their autonomy supportive behavior towards their students, however, these

6 authors did not measure controlling behaviors. As a further extension to Taylor and

7 colleagues' work, we proposed that the relationship between psychological need satisfaction

8 and perceived interpersonal behavior would be mediated by psychological well-being.

\section{$9 \quad$ Basic Psychological Needs and Psychological Well-Being}

Psychological well-being has been described as the experience of happiness and

11 pleasure (Diener, 1994), however, Ryan and Deci (2001) contend that well-being is not merely a reflection of positive affect, but also consists of a sense of eudaimonia. This concept refers to an individual achieving an integrated sense of self and realizing their human potential in terms of optimal psychological growth and development (Ryan \& Deci, 2001).

The notion of subjective vitality (i.e., a state of high positive energy emanating from the self) was developed within the SDT framework to encompass this eudaimonic definition of wellbeing (Ryan \& Frederick, 1997).

In view of this conceptualization of well-being, it is clearly important for sports coaches, as human beings, to be psychologically well and function optimally in their coaching roles (Allen \& Shaw, 2009). Supporters of BPNT consider the fulfilment of the

21 three psychological needs to be essential in the promotion and maintenance of psychological well-being (Deci \& Ryan, 2000), a proposal that has been supported in previous athlete-based research using a variety of research methods. For example, Adie, Duda, and Ntoumanis

24 (2008), using a cross-sectional design, found that perceptions of competence, autonomy and 25 relatedness positively predicted subjective vitality in a sample of team sport athletes. 
1 Similarly, Gagné, Ryan, and Bargmann (2003) conducted a diary-based study among female

2 gymnasts, and reported that fluctuations in daily satisfaction of competence, autonomy and

3 relatedness predicted changes in daily indices of well-being (i.e., subjective vitality, self

4 esteem, and positive affect). The existing sport-related BPNT research has, however, been

5 conducted solely with athlete or student populations, ignoring the psychological needs and

6 well-being of coaches. Testing the propositions of BPNT in the coaching population would

7 provide insight into the social-contextual ingredients required for coaches to flourish within

8 the coaching environment. Accordingly, it was hypothesized that coaches' competence,

9 autonomy and relatedness would positively predict their psychological well-being.

10 Psychological Well-being and Interpersonal Behavior

Surprisingly, researchers have yet to explore whether a psychologically healthy coach may interact more positively with their athletes, compared to a psychologically unhealthy coach, yet indirect evidence may provide a rationale for such a hypothesis. For example, in

14 the educational domain, high levels of work engagement (conceptualized as a positive, vigorous, fulfilling state of mind) have been shown to positively predict teachers’ instructional behaviors in the classroom (Klussman, Kunter, Trautwein, Lüdtke, \& Baumert, 2008). These behaviors included enabling students to develop new insight and understanding, proceeding at a pace appropriate to student needs, and creating a supportive social environment by showing patience with student mistakes, taking time to discuss problems, and giving personal guidance to students. This research suggests that coaches’ psychological well-being would positively predict autonomy support. Similarly, research has yet to consider the relationship between psychological wellbeing and a controlling interpersonal style. However, research in alternative contexts suggests

24 a link between various concepts associated with poor psychological health (e.g., narcissism, 25 psychopathic tendency) and aggressive, hostile, and dominant interpersonal styles (e.g., de 
1 Zavala, Cichocka, Eidelson, \& Jayawickreme, 2009; Hillege, Das, \& de Ruiter, 2010).

2 Therefore, it seems reasonable to suggest that a negative relationship would exist between

3 psychological well-being and controlling behaviors in sports coaches. Despite this limited

4 evidence, there is a need to extend theoretical knowledge and explore the relationships among

5 psychological well-being and autonomy supportive and controlling interpersonal styles.

\section{Summary and Hypotheses}

7

8
A considerable amount of SDT-based research has explored how coaches’ interpersonal behavior can influence athletes’ psychological well-being, basic psychological need satisfaction, self-determined motivation and performance (Amorose, 2007; Gillet et al., 2010; Mageau \& Vallerand, 2003). However, scant research has considered potential antecedents of coaches' interpersonal style. Based on the theoretical and empirical work discussed above (e.g., Hillege et al., 2010; Klussman et al., 2008; Deci \& Ryan, 2000), we examined a process model of potential antecedents of perceived coach autonomy supportive and controlling behaviors (see Figure 1).

First, it was hypothesized that coaches' satisfaction of competence, autonomy, and relatedness would positively predict their psychological well-being. Based on theoretical (e.g., Deci \& Ryan, 2000) and empirical research (e.g., Sheldon \& Bettencourt, 2002), we also hypothesized that the three psychological needs would be related. In turn, psychological well-being was proposed to positively predict coaches’ perceptions of their autonomy support towards their athletes and negatively predict perceptions of their controlling behaviors. These hypothesized relationships between psychological well-being and interpersonal behavior have not been previously explored. Existing research has demonstrated a moderate negative correlation between coach autonomy supportive and controlling behaviors (Pelletier et al., 2001), hence, we proposed a similar relationship. In addition, certain items employed in the current study, particularly those regarding coaches’ interpersonal behaviors, were potentially 
1 susceptible to socially desirable responses. Therefore, we included a measure of social

2 desirability to account for this possibility; something which has been overlooked in previous

3 sport research.

Finally, to more fully explore the mechanisms posited by our hypothesized model and

5 to further extend theoretical knowledge, we tested whether the relationships between the

6 three psychological needs and the two interpersonal styles would be mediated by coaches'

7 psychological well-being. By doing so, we aim to offer initial, albeit cross-sectional, evidence

8 that satisfying the psychological needs of one person may lead them to behave in ways which

9 create an adaptive interpersonal environment for others. This concept has scarcely been

10 addressed in the extant literature.

\section{Method}

\section{Participants and Procedures}

Participants were 443 coaches (313 male, 130 female; $M$ age $=41.06$ years, $S D=$

14 14.24, range $=18-75$ years) currently engaged in coaching practices. These demographics are 15 comparable to the general coaching population in the UK (Timson-Katchis \& North, 2010).

16 Coaches had, on average, $11.12(S D=10.02)$ years of coaching experience, and spent 12.87

$17 \quad(S D=12.88)$ hours per week coaching. Participants reported coaching one of 34 individual and team sports, and operated at a variety of competitive levels including recreational $(n=$ 52), club $(n=174)$, regional $(n=73)$, national $(n=80)$ and international/professional $(n=$

64). Following approval from a university ethical advisory committee, coaches were recruited

21 through national governing body databases, personal contacts, and sports club websites.

22 Prospective participants were provided with detailed information that fully explained the

23 purpose and procedures of the research, and were made aware that their involvement was

24 anonymous and voluntary. Coaches who consented to participate then completed a multi-

25 section questionnaire that took approximately 15 minutes to complete. 


\section{Measures}

Psychological need satisfaction. Satisfaction of competence, autonomy and

3 relatedness was measured using the Basic Need Satisfaction at Work Scale (BNSAW; Deci et

4 al., 2001) adapted to the coaching context. In line with modifications suggested by

5 Ntoumanis (2005), only the 12 positively worded items were used. Competence was assessed

6 using three items (e.g., "Most days I feel a sense of accomplishment from coaching),

7 autonomy was assessed using four items (e.g., "I am free to express my ideas and opinions

8 when coaching”), and relatedness was assessed using five items (e.g., "People I work with in

9 my coaching role care about me”). Coaches were asked to rate how true each of the

10 statements were for their given coaching experiences over the last month, on a scale ranging

11 from 1 (not at all true) to 7 (very true). Ntoumanis (2005) reported adequate factorial validity and internal consistency of the three subscales.

Psychological well-being. Items assessing coaches’ positive affect and subjective

14 vitality were used as indicators of a latent psychological well-being factor. Positive affect was measured using the 10-item positive affect subscale from the Positive and Negative Affect Scale (Watson, Tellegen, \& Clark, 1988). Coaches indicated the extent to which they had experienced positive emotions (e.g., “enthusiastic”, "proud” and "alert”) whilst coaching during the last month, on a five-point scale ranging from 1 (not at all or very slightly) to 5 (extremely). Watson et al. (1988) reported acceptable factorial validity and internal consistency of the subscale.

22 Scale (Ryan \& Frederick, 1997), which assessed the degree to which participants felt 23 psychologically vigorous and energized whilst coaching during the last month. Items were 24 preceded by the stem, “When I am coaching...” (e.g., "When I am coaching, I feel alive and 25 vital”), and required participants to rate their experiences on a seven-point scale ranging from 
11 (not at all true) to 7 (very true). One item was a negative statement and was therefore

2 reverse-scored prior to data analysis. Previous research has found the scale to have good

3 internal consistency and factorial validity (e.g., Bostic, Rubio, \& Hood, 2000; Ryan, \&

4 Frederick, 1997).

5

Coach autonomy supportive behaviors. The six-item version of the Health Care

6 Climate Questionnaire (HCQ; Williams, Grow, Freedman, Ryan, \& Deci, 1996) adapted to

7 the sport context, was used to assess coaches' perceptions of their autonomy supportive

8 behavior. Previous research has adapted the HCQ items to explore athlete perceptions of

9 coach autonomy support, and found them to have acceptable predictive validity and internal

10 consistency (e.g., Reinboth, Duda, \& Ntoumanis, 2004). Participants were asked to reflect on

11 their coaching practices over the last month and rate the extent to which they agreed with each of the items (e.g., "I provide my athletes with choices and options”) on a seven-point scale anchored by 1 (strongly disagree) and 7 (strongly agree).

Coach controlling behaviors. Coaches’ perceptions of their use of controlling behaviors were assessed using the 15-item Controlling Coach Behaviors Scale (CCBS;

16 Bartholomew et al., 2010), which was modified to reflect a coach's perspective. The scale measures four types of controlling behaviors, including coaches' controlling use of rewards (e.g., "I try to motivate my athletes by promising to reward them if they do well”), negative conditional regard (e.g., "I pay my athletes less attention if they displease me”), intimidation (e.g., "I embarrass my athletes in front of others if they do not do certain things”), and excessive personal control (e.g., "I try to control what my athletes do during their free time”).

22 Bartholomew et al. (2010) reported acceptable factorial validity and internal consistency of 23 the scale. 
1 questions in a socially desirable manner. Coaches were required to rate 10 items as either true

2 or false. A socially desirable response carried a weighting of one, with a non-socially

3 desirable answer scoring zero. The scores were then summed to produce a social desirability

4 score for each participant. Reynolds (1982) reported that the scale had acceptable concurrent 5 validity.

\section{Results}

\section{Preliminary Analyses}

Preliminary screening revealed no systematic patterns of missing data (1.13\%),

9 therefore, the expectation maximization algorithm (Dempster, Laird, \& Rubin, 1977) was

10 used to impute missing values. Next, confirmatory factor analysis (CFA) using the robust

11 maximum likelihood method with EQS software (version 6.1; Bentler, 2003) was employed

12 to determine the factor structure of the scales utilized. To evaluate the factorial structure of

13 the scales, a combination of fit indices were examined. The comparative fit index (CFI) was

14 chosen as an incremental fit index, and the standardized root mean square residual (SRMR)

15 and the root mean square error of approximation (RMSEA) represented absolute fit indices.

16 Hu and Bentler (1999) proposed that acceptable fit of a hypothesized model to the data is

17 indicated when the CFI is close to .95, the SRMR is close to .08, and the RMSEA is close to

18.06 . However, it is worth noting that these criteria may be overly restrictive when testing

19 complex models (Marsh, Hau, \& Wen, 2004). The BNSAW was found to have poor factor

20 structure: Satorra-Bentler $\chi^{2}(51)=146.75, p<.001$; CFI $=.88$; SRMR $=.05$; RMSEA $=.07$

21 (90\% Confidence Interval $[\mathrm{CI}]=.05-.08)$. Examination of the standardized loadings and

22 modification indices revealed the need to remove one item from each of the three subscales

23 (competence, "people tell me I am good at coaching”; autonomy, "I feel like I can make a lot

24 of inputs into deciding how my coaching gets done"; and relatedness, "I get along with

25 people when coaching”). This revised BNSAW showed satisfactory factor structure: Satorra- 
1 Bentler $\chi^{2}(24)=69.25, p<.001$; CFI $=.93$; SRMR $=.04$; $\mathrm{RMSEA}=.07(\mathrm{CI}=.05-.08)$.

2 Variable reduction procedures of this nature are justified because the original structure is

3 retained, but with only the best performing indicators (Hofmann, 1995).

4

5 constructs (Cortina, 1993). Coaches reported levels of competence, autonomy, relatedness,

Similarly, the positive affect scale required some amendment: Satorra-Bentler $\chi^{2}(35)$ $=113.81, p<.001 ; \mathrm{CFI}=.91 ; \mathrm{SRMR}=.05 ; \mathrm{RMSEA}=.07$ (CI $=.06-.09)$. Modification indices suggested the removal of the item, “excited”, after which the scale showed satisfactory factorial structure: Satorra-Bentler $\chi^{2}(27)=64.27, p<.001$; CFI $=.95$; SRMR $=$ .04 ; RMSEA $=.06(\mathrm{CI}=.04-.07)$. Lastly, the CFA for the CCBS also revealed inadequate factor structure: Satorra-Bentler $\chi^{2}(86)=212.57, p<.001$; CFI $=.89$; SRMR $=.06$; RMSEA $=.06(\mathrm{CI}=.05-.07)$. Inspection of the modification indices led to the removal of one item from the Intimidation subscale ("I intimidate my athletes into doing things that I want”), which led to acceptable factor structure: Satorra-Bentler $\chi^{2}(73)=142.75, p<.001$; CFI $=$ $.94 ;$ SRMR $=.05 ;$ RMSEA $=.05(\mathrm{CI}=.04-.06)$. The scales assessing subjective vitality: Satorra-Bentler $\chi^{2}(14)=38.71, p<.001 ; \mathrm{CFI}=.98$; SRMR $=.03$; RMSEA $=.06(\mathrm{CI}=.04-$ .09), and coach autonomy supportive behaviors: Satorra-Bentler $\chi^{2}(9)=23.32, p<.001$; CFI $=.95 ; \mathrm{SRMR}=.03 ; \mathrm{RMSEA}=.06(\mathrm{CI}=.03-.09)$ were found to have acceptable factorial structure.

\section{Descriptive Statistics and Scale Reliabilities}

The means, standard deviations, and Cronbach’s alpha coefficients were calculated for each subscale and are presented in Table 1. All subscales demonstrated good internal reliability $(\alpha>$.70), with the exception of the competence and autonomy subscales, which were deemed adequate $(\alpha>$.60) given the low number of items used to measure these positive affect, subjective vitality, autonomy support, and social desirability above the 
1 midpoint of the respective scales, and levels of controlling behaviors below the midpoint of

2 the scale.

The correlations between all variables are shown in Table 1 . There was no evidence

4 of multicollinearity as all correlations were below .70 (Tabachnick \& Fidell, 1996). In line

5 with the theoretical predictions of BPNT, competence, autonomy, and relatedness needs were

6 moderately and positively correlated with each other. The three psychological needs were

7 moderately and positively correlated with positive affect, subjective vitality, and autonomy

8 support, and negatively correlated with controlling behaviors. Both positive affect and

9 subjective vitality were moderately and positively correlated with each other and autonomy

10 support, and negatively, albeit weakly, correlated with controlling behaviors. Coach

11 autonomy supportive and controlling behaviors were moderately and negatively correlated

12 with each other.

\section{A Structural Model of Antecedents of Perceived Coach Behaviors}

14 The proposed model was tested using the robust maximum likelihood estimation

15 method (Mardia's normalized estimate of multivariate kurtosis $=41.00$ ). Within the model

16 (see Figure 1), the study variables were represented by latent factors (with the exception of

17 social desirability). The two items measuring competence, the three items measuring

18 autonomy, and the four items measuring relatedness were used as indicators of three latent

19 factors representing the psychological needs. The positive affect and subjective vitality

20 subscales were used as indicators of coaches' psychological well-being. The six items

21 measuring perceived autonomy supportive behaviors were used as indicators of an autonomy

22 support latent factor, and the four subscales of the CCBS were used as indicators of coaches'

23 perceived controlling behaviors. Finally, social desirability was represented by a single

24 observed variable. As autonomy supportive and controlling behaviors were dependent

25 variables in the hypothesized model, their interrelationship can only be accounted for by 
1 correlating their error terms within EQS 6.1. Standardized factor loadings and uniqueness

2 terms of the indicators used in the structural model (median loading of item indicators $\beta=$

3 .68) are shown in Table 2.

Model fit indices revealed that the proposed model fit the data well: Satorra-Bentler

$5 \chi^{2}(199)=344.66, p<.001 ; \mathrm{CFI}=.92 ; \mathrm{SRMR}=.05 ; \mathrm{RMSEA}=.04(\mathrm{CI}=.03-.05)$. The

6 pathway between relatedness need satisfaction and psychological well-being was non-

7 significant, as was the pathway between social desirability and perceived autonomy

8 supportive behaviors. Moderate to strong associations among competence, autonomy and

9 psychological well-being were found. In turn, psychological well-being was a strong positive

10 predictor of perceived autonomy supportive behavior, and a moderate negative predictor of

11 perceived controlling behavior. Also, a moderate negative relationship between social

12 desirability and perceived controlling behaviors was found. Coaches' need satisfaction

13 accounted for $70 \%$ of the variance in their psychological well-being. Moreover, well-being

14 explained 54\% and 16\% of the variance in coaches' perceived use of autonomy supportive

15 and controlling behaviors, respectively.

\section{Mediation Effects}

17 Mediation analyses were conducted to test whether the relationships among autonomy

18 and competence need satisfaction and the two coach interpersonal styles were mediated by

19 psychological well-being. For mediation effects to be present, significant paths should be

20 evident between the independent variables and the mediator, and also the mediator and the

21 outcome variables (Holmbeck, 1997). Relatedness need satisfaction was, therefore, not

22 included in the mediation analyses because it did not show a significant relationship with the

23 mediator (psychological well-being). We first constructed a constrained model, in which

24 indirect pathways between competence and autonomy need satisfaction and the coach

25 behaviors via psychological well-being were estimated: Satorra-Bentler $\chi^{2}(129)=227.19, p$ 
$1<.001 ; \mathrm{CFI}=.93 ; \mathrm{SRMR}=.05 ; \mathrm{RMSEA}=.04(\mathrm{CI}=.03-.05)$. Next, we constructed an

2 unconstrained model, in which direct and indirect pathways between the psychological needs

3 and coach behaviors were estimated. According to Holmbeck (1997), mediation exists if the

4 unconstrained model does not show significant improvement in fit compared to the

5 constrained model. Although, the unconstrained model demonstrated acceptable fit: Satorra-

6 Bentler $\chi^{2}(125)=219.81, p<.001 ; \mathrm{CFI}=.93 ; \mathrm{SRMR}=.05 ; \mathrm{RMSEA}=.04(\mathrm{CI}=.03-.05)$, a

7 non-significant Sattora-Bentler chi-square difference test (Satorra \& Bentler, 2001) indicated

8 that the mediated model (i.e., our constrained model) was more parsimonious $\left(\Delta \chi^{2}=7.37\right.$,

$9 \Delta d f=4, p>.05)$. To ascertain the significance of each mediation pathway, a series of Sobel

10 tests (Sobel, 1982) were conducted. All four mediation pathways, between competence need

11 satisfaction and perceived autonomy supportive behavior, $(Z=4.21, p<.001)$, competence

12 need satisfaction and perceived controlling behavior, $(Z=-3.18, p<.01)$, autonomy need

13 satisfaction and perceived autonomy supportive behavior, $(Z=2.43, p<.05)$, and autonomy

14 need satisfaction and perceived controlling behavior $(Z=-2.17, p<.05)$, were significant.

Discussion

The purpose of the present study was to test a model of potential antecedents of

17 perceived coach autonomy supportive and controlling behaviors using the SDT framework

18 (Deci \& Ryan, 2000). The results suggest that satisfaction of coaches’ basic psychological

19 needs for autonomy and competence, but not relatedness, positively predicted their

20 psychological well-being. Furthermore, coaches’ psychological well-being was found to

21 positively predict their perceived use of autonomy support, and negatively predict their

22 perceived use of controlling behaviors after taking into account coaches' tendency to provide

23 socially desirable responses. When taken in its entirety, the proposed mediation model

24 advances the existing literature by suggesting that supporting coaches’ psychological needs

25 may help to indirectly create a positive autonomy supportive, non-controlling environment 
1 for athletes by allowing coaches to psychologically thrive. This process has not previously

2 been addressed in any context, as very little SDT-based literature has examined interpersonal

3 behavior as an outcome of psychological need satisfaction. In the following sections we

4 discuss each step of the mediation process in turn.

\section{Basic Psychological Needs and Psychological Well-Being}

In the present study, basic psychological need satisfaction explained $70 \%$ of the

7 variance in psychological well-being, which is comparable to previous research in the sport

8 domain (e.g., Quested \& Duda, 2010). Aligned with BPNT and previous research with

9 athletes (Adie et al., 2008; Gagné et al., 2003; Quested \& Duda, 2010; Reinboth et al., 2004),

10 the results of the present study suggest that coaches' autonomy need satisfaction is positively

11 related to their psychological well-being. This is consistent with Ryan and Frederick's (1997) argument that autonomy plays a crucial role in the development of psychological health, as well-being cannot be attained when a person feels controlled in their actions. Thus, coaches who experience a sense of volition and feel that they are the origin of their behavior may psychologically thrive within their coaching role. In comparison, coaches who feel powerless and controlled to engage in certain coaching practices may experience lower psychological

17 well-being. This implies that significant social agents within the coaching environment (e.g., head coaches, performance directors, club managers) should provide coaches with a sense of autonomy by allowing them opportunities for decision-making and personal input with regards to how they conduct training sessions, how they manage their athletes, and how they optimally prepare individuals and teams for competition. These social agents may also support coaches' sense of autonomy by acknowledging coaches' feelings and perspectives, engaging in two-way feedback processes, and providing them with input into the organization

24 itself (Allen \& Shaw, 2009). 
Within the present study, competence emerged as the strongest predictor of psychological well-being. This finding is consonant with previous athlete-based research

3 (e.g., Adie et al., 2008; Quested \& Duda, 2010; Reinboth et al., 2004). Therefore, sport clubs

4 should aim to facilitate coaches' perceptions of competence by offering continued

5 professional development via training courses, providing coaches with positive and

6 instructional feedback concerning their coaching techniques, and by structuring clear and 7 progressive coaching goals.

Contrary to our hypothesis, relatedness need satisfaction did not predict coaches’

9 psychological well-being. This is inconsistent with previous work in which relatedness

10 predicted positive affect (Quested \& Duda, 2010) and subjective vitality (Adie et al., 2008) in

11 team sport and vocational dance contexts. Nonetheless, Deci and Ryan (2000) proposed that,

12 in certain contexts, relatedness may play a more distal role with regards to the development

13 and maintenance of psychological growth and well-being, compared to competence and

14 autonomy. Indeed, the athletes studied in previous research were engaged in team sports,

15 whereas the majority of coaches in the present study (approximately 74\%), operated within

16 individual sports. Furthermore, the dancers studied in previous research existed within an

17 explicit social group of dancers who they lived with, whereas many coaches tend to work in

18 the absence of a peer group of other coaches. Despite these possible explanations, researchers

19 adopting alternative theoretical frameworks may not subscribe to such a diminished role of

20 relatedness in certain contexts (e.g., Leary \& Baumeister, 2000). Therefore, it seems

21 necessary to further explore the underlying reasons for the lack of association between

22 relatedness and well-being in certain contexts. Examining potential differences between team

23 and individual sports may represent such a research avenue.

\section{Psychological Well-Being and Interpersonal Behavior}



to help create an optimal coach-created environment for athletes.

\section{Future Directions and Limitations}


The findings in the present study can be extended in several ways. First, the data were cross-sectional in nature, therefore, we cannot clarify the direction of relationships within the model. This is particularly important with regards to the mediation analysis, which warrants caution when interpreting the results. We cannot dismiss the possibility of reverse causality (Kenny, Kashy, \& Bolger, 1998) between the outcome variables (perceived autonomy support and control) and the mediating variable (psychological well-being). Nonetheless, our cross-sectional model was based on sound theory and prior research. Furthermore, Kenny et al. (1998) highlight that if the predictor, mediator and outcome variables are measured at the same point in time multicollinearity is possible. In the current study, however, the bivariate correlations among the variables were not excessively large ( $r=-.33$ to .59 ), indicating that multicollinearity was not an issue. With these limitations in mind, cross-lagged longitudinal or experimental designs are needed to clarify our proposed process model.

Second, the present work relied upon self-report instruments to measure the study variables. In particular, measurement of coaches’ perceived interpersonal behaviors may not be an accurate reflection of actual behaviors. Although the inclusion of a social desirability measure went some way to surmount any potential bias, objective assessments of coaches' behavior (e.g., independent observations) may build upon this work. Moreover, athletes’ perceptions of coach behavior would complement coaches’ self-reports, especially as athletes' perceptions of the motivational environment are most pertinent in predicting athlete consequences (i.e., functional significance; Deci \& Ryan, 1987).

Another limitation surrounds the necessary modifications to the BNSAW scale to measure coaches’ basic psychological need satisfaction. Modifications left the competence subscale with only two items, which may have posed problems concerning empirical underidentification. We retained the competence subscale, however, because the model converged, no negative error variances were found (a sign of empirical under-identification) and both 
1 items loaded strongly onto the competence latent factor (i.e., >.40; Ford, MacCallum, \& Tait,

2 1986; see Table 2), suggesting that using two indicators in this instance was not problematic.

3 In view of the modifications, however, it may be worthwhile for researchers to devise a

4 coach-specific measure to assess basic psychological need satisfaction in this population.

5 This may be particularly important given Allen and Shaw's (2009) call for increased attention

6 on coaches’ psychological needs and well-being.

$7 \quad$ Our hypothesized model can also be extended from a theoretical and practical

8 perspective. SDT-based research provides insight into how the social environment can satisfy

9 one’s basic psychological needs (and psychological well-being). For example, Allen and

10 Shaw (2009) highlighted that a lack of assistance and guidelines from sport organizations,

11 and a lack of opportunities for formal training, feedback and networking with other coaches,

12 may lead to the frustration of coaches' psychological needs. Taylor et al. (2008) also reported

13 that contextual factors such as pressures from school administration, evaluation pressures,

14 and time constraints within the lesson served to negatively impact upon physical education

15 teachers' basic psychological need satisfaction. It would be intriguing to determine how

16 coaches experience environmental demands, such as time constraints to optimally prepare

17 athletes for competition, pressures regarding administration and finances, evaluations based on athlete performance, and pressure from superiors. These pressures may differ according to

19 whether a coach is in a paid or voluntary role, as well as an assistant coach or head coach

20 position. The current study was conducted with both full- and part-time coaches, at various

21 competitive levels. While this provides an opportunity to generalize our results across

22 different coaching sub-populations, future research may look to establish how the

23 relationships proposed in the model vary as a function of job status (e.g., full-time versus

24 part-time) and competitive level. An assessment of these contextual influences on basic 
1 psychological need satisfaction would extend the current model by providing insight into how

2 the coaching environment may lead to the sequence of effects demonstrated in this study.

\section{Conclusions}

4 The present study advances the current literature in a number of ways. No previous

5 research has examined psychological need satisfaction and well-being in a coaching

6 population. The findings, therefore, facilitate our understanding of the importance of

7 promoting need satisfaction in the coaching context. Moreover, this study is the first to

8 concurrently explore the relationships among psychological well-being, autonomy supportive

9 and controlling interpersonal behaviors. Apart from a few exceptions, coaches’ controlling

10 interpersonal style has been largely ignored in the extant literature, however, the current

11 investigation outlines a promising conceptual approach for understanding the mechanisms

12 behind coach interpersonal behavior. Overall, the key finding of the study is that satisfaction

13 of coaches' psychological needs may allow coaches to thrive, and to create an adaptive

14 interpersonal coaching environment for athletes. 


\section{References}

2 Adie, J. W., Duda, J. L., \& Ntoumanis, N. (2008). Autonomy support, basic need satisfaction and the optimal functioning of adult male and female sport participants: A test of basic needs theory. Motivation and Emotion, 32, 189-199. doi:10.1007/11031-008-9095-z

Allen, J. B., \& Shaw, S. (2009). Women coaches’ perceptions of their sport organizations’

6 social environment: Supporting coaches’ psychological needs? The Sport Psychologist, 23, 346-366. Retrieved from http://journals.humankinetics.com/tsp

Amorose, A. J. (2007). Coaching effectiveness. In M. S. Hagger \& N. L. D. Chatzisarantis (Eds.), Intrinsic motivation and self-determination in exercise and sport (pp. 209-227). Leeds: Human Kinetics.

Baard, P. P., Deci, E. L., \& Ryan, R. M. (2004). Intrinsic need satisfaction: A motivational basis of performance and well-being in two work-settings. Journal of Applied Social Psychology, 34, 2045-2068. doi:10.1111/j.1559-1816.2004.tb02690.x

Bartholomew, K., Ntoumanis, N., \& Thøgersen-Ntoumani, C. (2009). A review of controlling motivational strategies from a self-determination theory perspective: Implications for sports coaches. International Review of Sport and Exercise Psychology, 2, 215-233. doi:10.1080/17509840903235330

Bartholomew, K., Ntoumanis, N., \& Thøgersen-Ntoumani, C. (2010). The controlling interpersonal style in a coaching context: Development and initial validation of a psychometric scale. Journal of Sport \& Exercise Psychology, 32, 193-216. Retrieved from http://journals.humankinetics.com/jsep

Baumeister, R., \& Leary, M. R. (1995). The need to belong: Desire for interpersonal attachments as a fundamental human motivation. Psychological Bulletin, 117, 497-529. Retrieved from http://www.apa.org/pubs/journals/bul/ 
1 Bentler, P. M. (2003). EQS 6.1 for Windows [Computer software]. Encino, CA: Multivariate Software.

3 Bostic, T. J., Rubio, D. M., \& Hood, M. (2000). A validation of the subjective vitality scale

4

5 using structural equation modeling. Social Indicators Research, 52, 313-324. doi:10.1023/A:1007136110218

Cortina, J. M. (1993). What is coefficient alpha? An examination of theory and applications. Journal of Applied Psychology, 78, 91-104. doi: 10.1037/0021-9010.78.1.98

deCharms, R. (1968). Personal causation: The internal affective determinants of behavior. NewYork: Academic Press.

Deci, E. L., \& Ryan, R. M. (1987). The support of autonomy and the control of behavior. Journal of Personality and Social Psychology, 53, 1024-1037. doi:10.1037/0022-3514.53.6.1024

Deci, E. L., \& Ryan, R. M. (2000). The “what” and “why” of goal pursuits: Human needs and the self-determination of behavior. Psychological Inquiry, 11, 227-268. doi:10.1207/S15327965PLI1104_01

Deci, E. L., Ryan, R. M., Gagné, M., Leone, D. R., Usunov, J., \& Kornazheva, B. P. (2001). Need satisfaction, motivation, and well-being in the work organizations of a former Eastern Bloc country: A cross-cultural study of self-determination. Personality and Social Psychology Bulletin, 27, 930-942. doi:10.1177/0146167201278002

Dempster, A. P., Laird, N., \&. Rubin, D. B. (1977). Maximum likelihood from incomplete data via the EM algorithm. Journal of the Royal Statistical Society, B, 39, 1-38.

deZavala, A. G., Cichocka, A., Eidelson, R., \& Jayawickreme, N. (2009). Collective narcissism and its social consequences. Journal of Personality and Social Psychology, 97, 1074-1096. doi:10.1037/a0016904 
1 Diener, E. (1994). Assessing subjective well-being: Progress and opportunities. Social Indicators Research, 31, 103-157. doi:10.1007/BF01207052

3 Ford, J., MacCallum, R., \& Tait, M. (1986). The application of factor analysis in psychology:

4

5

A critical review and analysis. Personnel Psychology, 39, 291-314. doi:10.1111/j.1744-6570.1986.tb00583.x

Fraser-Thomas, J., \& Côté, J. (2009). Understanding adolescents’ positive and negative developmental experiences in sport. The Sport Psychologist, 23, 3-23. Retrieved from http://journals.humankinetics.com/tsp

Gagné, M., Ryan, R.M., \& Bargmann, K. (2003). Autonomy support and need satisfaction in the motivation and well-being of gymnasts. Journal of Applied Sport Psychology, 15, 372-390. doi:10.1080/714044203

Gillet, N.,Vallerand, R. J., Amoura, S., \& Baldes, B. (2010). Influence of coaches’ autonomy support on athletes' motivation and sport performance: A test of the hierarchical model of intrinsic and extrinsic motivation. Psychology of Sport and Exercise, 11, 155-161. doi:10.1016/j.psychsport.2009.10.004

Harter, S. (1978). Effectance motivation reconsidered: Toward a developmental model. Human Development, 21, 34-64. doi:10.1159/000271574

Hillege, S., Das, J., \& de Ruiter, C. (2010). The youth psychopathic traits inventory: Psychometric properties and its relation to substance use and interpersonal style in a dutch sample of non-referred adolescents. Journal of Adolescence, 33, 83-91. doi:10.1016/j.adolescence.2009.05.006

Hofmann, R. (1995). Establish factor validity using variable reduction in confirmatory factor analysis. Educational and Psychological Measurement, 55, 572-582. doi:10.1177/0013164495055004005 
1 Holmbeck, G. N. (1997). Toward terminological, conceptual, and statistical clarity in the study of mediators and moderators: Examples from child-clinical and pediatric psychology literatures. Journal of Consulting and Clinical Psychology, 65, 599-610. doi:10.1037/0022-006X.65.4.599

Horn, T. S. (2008). Coaching effectiveness in the sport domain. In T. S. Horn (Ed.), Advances in sport psychology (pp. 239-268). Champaign, IL: Human Kinetics.

Hu, L., \& Bentler, P. M. (1999). Cut-off criteria for fit indexes in covariance structure analysis: Conventional criteria versus new alternatives. Structural Equation Modeling, 6, 1-55. doi:10.1080/10705519909540118

Kenny, D. A., Kashy, D. A., \& Bolger, N. (1998). Data analysis in social psychology. In D. T. Gilbert, S. T. Fiske, \& G. Lindzey (Eds.), The handbook of social psychology (pp. 233-265).

Klussman, U., Kunter, M., Trautwein, U., Lüdtke, O., \& Baumert, J. (2008). Teachers’ occupational well-being and quality of instruction: The important role of self-regulatory patterns. Journal of Educational Psychology, 100, 702-715. doi:10.1037/0022-0663.100.3.702

Leary, M. R., \& Baumeister, R. F. (2000). The nature and function of self-esteem: Sociometer theory. In M. P. Zanna (Ed.), Advances in experimental social psychology, (Vol 32, pp. 1-62). San Diego, CA: Academic Press.

Mageau, G. A., \& Vallerand, R. J. (2003). The coach-athlete relationship: A motivational model. Journal of Sports Sciences, 21, 883-904. doi:10.1080/0264041031000140374

Marsh, H. W., Hau, K., \& Wen, Z. (2004). In search of golden rules: Comment on hypothesis-testing approaches to setting cutoff values for fit indexes and dangers in overgeneralizing Hu and Bentler’s (1999) findings. Structural Equation Modeling, 11, 320-341. doi:10.1207/s15328007sem1103_2 
1 Ntoumanis, N. (2005). A prospective study of participation in optional school physical education using a self-determination theory perspective. Journal of Educational Psychology, 97, 444-453. doi:10.1037/0022-0663.97.3.444

4

Pelletier, L. G., Fortier, M. S., Vallerand, R. J., \& Brière, N. M. (2001). Associations among perceived autonomy support, forms of self-regulation, and persistence: A prospective study. Motivation and Emotion, 25, 279-306. doi:10.1023/A:1014805132406

Quested, E., \& Duda, J. L (2010). Exploring the social-environmental determinants of welland ill-being in dancers: A test of basic needs theory. Journal of Sport \& Exercise Psychology, 32, 39-60. Retrieved from http://journals.humankinetics.com/jsep

Reinboth, M., Duda, J. L., \& Ntoumanis, N. (2004). Dimensions of coaching behavior, need satisfaction, and the psychological and physical welfare of young athletes. Motivation and Emotion, 28, 297-313. doi:10.1023/B:MOEM.0000040156.81924.b8

Reynolds, W. M. (1982). Development of reliable and valid short forms of the MarloweCrowne social desirability scale. Journal of Clinical Psychology, 38, 119-125. doi:10.1002/1097-4679(198201)38:1<119::AID-JCLP2270380118>3.0.CO;2-I

Ryan, R. M., \& Deci, E. L. (2001). On happiness and human potentials: A review of research on hedonic and eudaimonic well-being. Annual Review of Psychology, 52, 141-166. Retrieved from http://www.annualreviews.org/loi/psych

Ryan, R. M., \& Frederick, C. M. (1997). On energy, personality and health: Subjective vitality as a dynamic reflection of well-being. Journal of Personality, 65, 529-565. doi:10.1111/j.1467-6494.1997.tb00326.x

Sarrazin, P., Vallerand, R. J., Guillet, E., Pelletier, L., \& Cury, F. (2002). Motivation and dropout in female handballers: A 21-month prospective study. European Journal of Social Psychology, 32, 395-418. doi:10.1002/ejsp.98 
1 Satorra, A., \& Bentler, P. M. (2001). A scaled difference chi-square test statistic for moment structure analysis. Psychometrika, 66, 507-514. doi:10.1007/BF02296192

Sheldon, K. M., \& Bettencourt, B. A. (2002). Psychological need-satisfaction and subjective well-being within social groups. British Journal of Social Psychology, 41, 25-38. Retrieved from http://www.bpsjournals.co.uk/journals/bjsp/

Sobel, M. E. (1982). Asymptomatic confidence intervals for indirect effects in structural equation models. Sociological Methodology, 13, 290-312.

Strahan, R., \& Gerbasi, K. C. (1972). Short, homogeneous versions of the Marlowe-Crowne social desirability scale. Journal of Clinical Psychology, 28, 191-193. doi:10.1002/1097-4679(197204)28:2<191::AID-JCLP2270280220>3.0.CO;2-G

Tabachnick, B. G., \& Fidell, L. S. (1996). Using multivariate statistics (3 ${ }^{\text {rd }}$ ed.). New York: Harper Collins.

Taylor, I. M., Ntoumanis, N., \& Standage, M. (2008). A self-determination theory approach to understanding the antecedents of teachers' motivational strategies in physical education. Journal of Sport \& Exercise Psychology, 30, 75-94. Retrieved from http://journals.humankinetics.com/jsep

Timson-Katchis, M., \& North, J. (2010). UK coach tracking study: Year two headline report. Retrieved from http://www.sportscoachuk.org/index.php?PageID=5\&sc=23\&uid=1856

Vallerand, R. J., \& Losier, G. F. (1999). An integrative analysis of intrinsic and extrinsic motivation in sport. Journal of Applied Sport Psychology, 11, 142-169. doi:10.1080/10413209908402956

Watson, D., Tellegen, A., \& Clark, L. (1988). Development and validation of brief measures of positive and negative affect: The PANAS scales. Journal of Personality and Social Psychology, 54, 1063-1070. doi:10.1037/0022-3514.54.6.1063 
1 Williams, G. C., Grow, V. M., Freedman, Z. R., Ryan, R. M., \& Deci, E. L. (1996). Motivational predictors of weight loss and weight-loss maintenance. Journal of Personality and Social Psychology, 70, 115-126. doi:10.1037/0022-3514.70.1.115

4 Wilson, P. M., Mack, D. E., Blanchard, C. M., \& Gray, C. E. (2009). The role of perceived psychological need satisfaction in exercise-related affect. Hellenic Journal of Psychology, 6, 183-206. Retrieved from http://www.pseve.org/journal.asp 
Table 1

Descriptive Statistics, Cronbach's Alphas and Correlations Between all Variables

\begin{tabular}{|c|c|c|c|c|c|c|c|c|c|c|c|}
\hline Variable & $M$ & $S D$ & $\alpha$ & 1. & 2. & 3. & 4. & 5. & 6. & 7. & 8. \\
\hline 1. Competence & 5.86 & 1.02 & .68 & - & & & & & & & \\
\hline 2. Autonomy & 5.35 & .96 & .61 & $.55^{* *}$ & - & & & & & & \\
\hline 3. Relatedness & 5.52 & 1.01 & .78 & $.46^{* *}$ & $.59 * *$ & - & & & & & \\
\hline 4. Positive Affect & 4.08 & .59 & .84 & $.47 * *$ & $.42 * *$ & $.35 * *$ & - & & & & \\
\hline 5. Vitality & 5.38 & .99 & .88 & $.45^{* *}$ & $.42 * *$ & $.34 * *$ & $.55^{* *}$ & - & & & \\
\hline 6. Autonomy Supportive Behaviors & 5.80 & .78 & .82 & $.46^{* *}$ & $.46^{* *}$ & $.42 * *$ & $.47 * *$ & $.44^{* *}$ & - & & \\
\hline 7. Controlling Behaviors & 2.23 & .82 & .83 & $-.15^{* *}$ & $-.21 * *$ & $-.21 * *$ & $-.10^{*}$ & $-.23 * *$ & $-.33 * *$ & - & \\
\hline 8. Social Desirability Index & 6.94 & 1.87 & - & .02 & .06 & $.12 *$ & .06 & $.10 *$ & $.12^{*}$ & $-.26 * *$ & - \\
\hline
\end{tabular}

Note. $* p<.05, * * p<.01$ 
Table 2

Standardized Factor Loadings and Uniqueness Terms of all Indicators in the Structural Equation Model

\begin{tabular}{lcc}
\hline Latent Factor and Observed Indicators & Loading & Uniqueness \\
\hline Competence & & \\
Item 1 & .62 & .78 \\
Item 2 & .83 & .55 \\
Autonomy & & \\
Item 1 & .69 & .73 \\
Item 2 & .46 & .89 \\
Item 3 & .72 & .69 \\
Relatedness & & .69 \\
Item 1 & .73 & .78 \\
Item 2 & .63 & .71 \\
Item 3 & .71 & .72 \\
Item 4 & .70 & .69 \\
Well-being & & .70 \\
Mean positive affect & .72 & .72 \\
Mean subjective vitality & .71 & .75 \\
Autonomy Supportive Behaviors & & .76 \\
Item 1 & .70 & .78 \\
Item 2 & .66 & .73 \\
Item 3 & .65 & .77 \\
Item 4 & .63 & .79 \\
Item 5 & .68 & .66 \\
Item 6 & .63 & .77 \\
Controlling Behaviors & & .87 \\
Mean controlling use of rewards & .61 &
\end{tabular}

Note. No factor loadings are available for social desirability because this construct is an independent variable reflected by a single-item composite score. 
Figure 1

Structural model of coach psychological need satisfaction, well-being and perceived use of autonomy supportive and controlling behaviors.

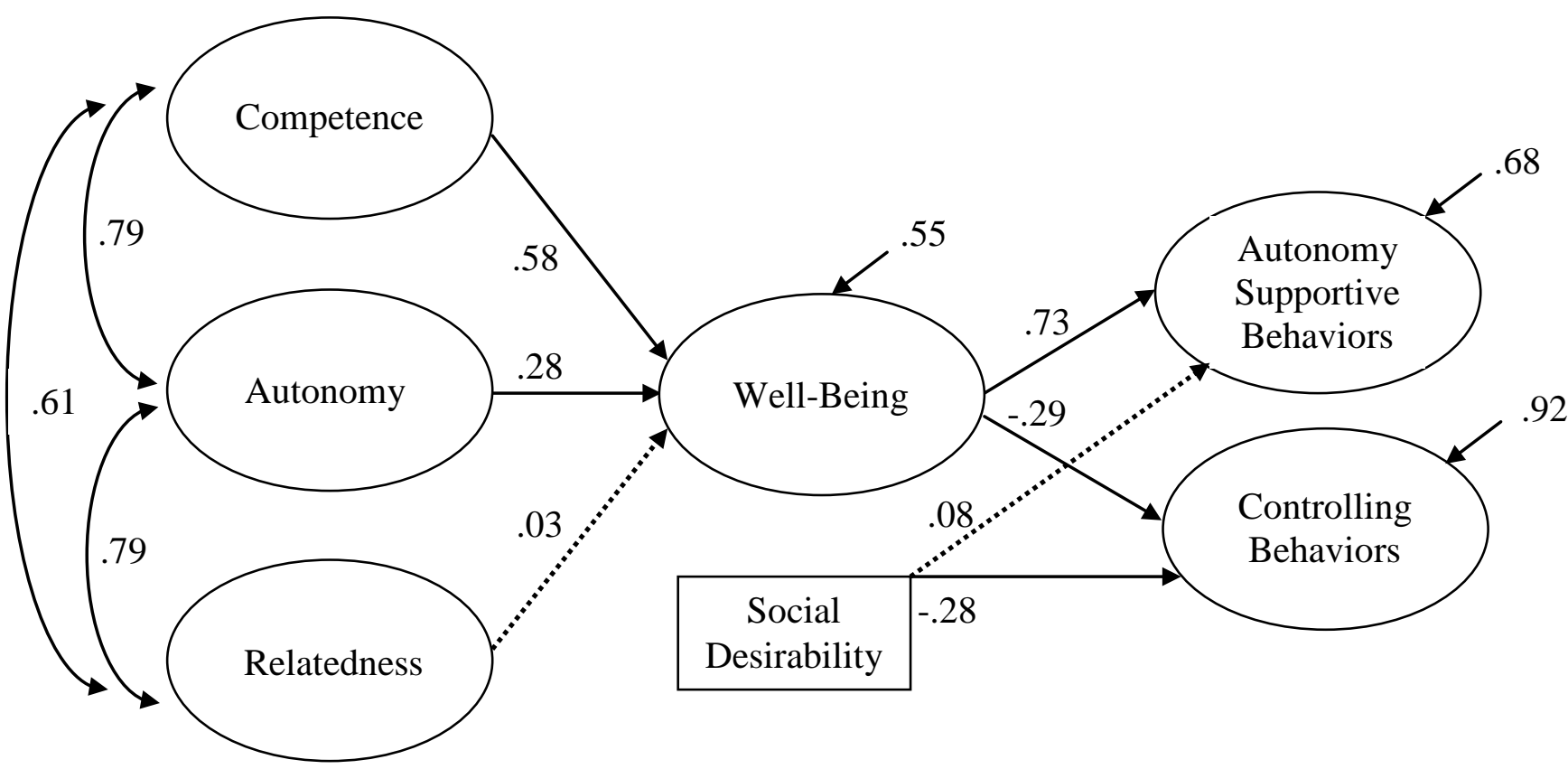

Note. All regression path coefficients are standardized and non-significant pathways $(p>.05)$ are denoted by dotted arrows. For presentation simplicity, factor indicators and the correlation of the error terms between perceived autonomy supportive and controlling behaviors $(r=-.32)$ are omitted. Coaches' need satisfaction accounted for $70 \%$ of the variance in their psychological well-being. Coaches' well-being accounted for 54\% and 16\% of the variance in their perceived use of autonomy supportive and controlling behaviors, respectively. 